\title{
PRODUCCIÓN DE SOYA TRANSGÉNICA Y MIEL EN YUCATAN, MÉXICO. IMPACTOS EN LA SUSTENTABILIDAD DE PRODUCTORES EN TEKAX ${ }^{1}$
}

\section{PRODUCTION OF TRANSGENIC SOYBEANS \\ AND HONEY IN YUCATAN, MEXICO. IMPACTS ON THE SUSTAINABILITY OF PRODUCERS IN TEKAX}

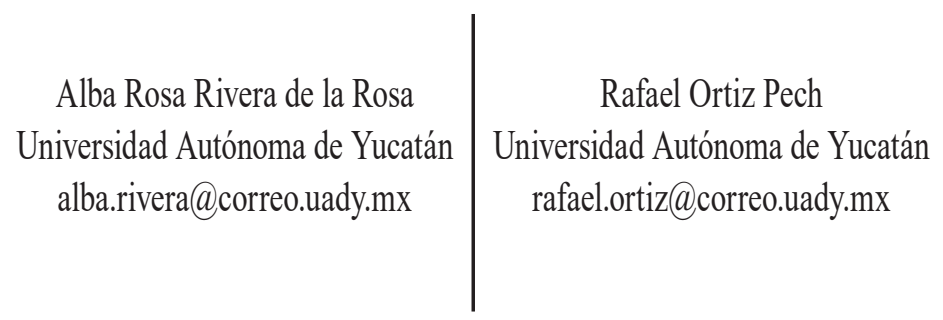

\section{RESUMEN}

La producción de soya en México se inserta dentro de las tendencias globales de las cadenas de valor cereales-carne en el tercer régimen alimentario. La soya transgénica se introduce en México a principios del siglo XXI y una de las consecuencias medio ambientales más cuestionadas de su producción es el uso intensivo del herbicida a base de glifosato, con graves consecuencias para la salud humana y medio ambiente. Los efectos de la producción de soya se dejan sentir en productores mecanizados de la zona de Tekax, Yucatán, afectando la selva primaria, los mantos freáticos y otras actividades que dependen de la biodiversidad de la región como la producción de miel, de la cual el estado de Yucatán es el primer productor en México. El objetivo del presente trabajo es conocer las condiciones de

1 Para esta investigación la Dra. Rivera de la Rosa realizó una estancia de investigación en Sevilla y Madrid en de enero de 2016, con recursos PROFOCIE 2014. 
producción económicas, medio ambientales y algunas de tipo social, de los productores de soya en el municipio de Tekax, Yucatán, México; lugar donde se introdujo por primera vez la producción de soya transgénica. En segundo lugar, se busca conocer el impacto de los cultivos agrointensivos como la soya, en la producción de miel en Tekax, ya que ambas actividades conviven en un mismo espacio territorial. Los resultados arrojan un alto nivel de contaminación en la producción de soya y un impacto positivo de los cultivos agrointensivos en la producción de miel.

Palabras clave: soya, glifosato, salud humana, miel, biodiversidad

\section{Clasificación JEL: Q51 YQ57}

\section{ABSTRACT}

Soybean production in Mexico is inserted into global trends of cerealmeat chain value under the third food regime. Genetically Modifyied (GM) soybean is introduced in Mexico at the beginning of XXI century and one of the more questionable environmental consequences of their production is the intensive use of the herbicide called glyphosate with serious consequences on human health and the environment. The results of soybean production are felt in mechanized producers in the area of Tekax, Yucatan, affecting primary forest, groundwater and other activities that depend on biodiversity of the region as honey production, which Yucatan is the first producer in México. The aim of this work is to know the conditions of soybean producers; social, environmental and economic aspects in the municipality of Tekax, Yucatan, Mexico; place where the GM soybean was first introduced in production. And secondly, know what is the impact of crops such as soybeans in the honey production in the region, since both activities coexist in the same territorial space. The results show a high level of contamination in soybean production and a positive impact of agro-intensive crops on honey production.

Keywords: soybeans, glyphosate, human health, honey, biodiversity. 


\section{INTRODUCCIÓN}

En los últimos años el tercer régimen alimentario establece una nueva tendencia global con respecto a la importancia de lo local, del medio ambiente y lo ecológico (McMichael, 2009a y 2009b; Winders, 2009). Ambos elementos, lo local y lo ecológico, no habían tenido un papel preponderante en los regímenes alimentarios anteriores.

En el primer régimen, las colonias y la primera división internacional del trabajo entre países industriales y países proveedores de materias primas son el escenario dominante de las revoluciones industriales que conllevaron, como parte intrínseca, el desgaste de las reservas ecológicas a escala mundial. El segundo régimen alimentario, bajo el dominio norteamericano y la revolución verde de los años cincuenta del siglo pasado, trajo consigo cambios tecnológicos que aceleraron la contaminación del medio ambiente, el uso de agroquímicos y el manejo de los monocultivos; asimismo han jugado un papel importante la incursión de semillas mejoradas y transgénicas. Los efectos de estas últimas no han sido evaluados y probados del todo y se sigue cuestionando su inocuidad en el consumo y comercialización (Swanson et al., 2014).

Desde la década de los años setenta del siglo XX, el tercer régimen alimentario plantea una nueva tendencia agroecológica que se vincula con las aportaciones de lo campesino, regional y local; no obstante, también se fortalecen en México, igual que en otros países, las cadenas de valor cereales-carne; la carne de res, cerdo y pollo se convierten en una proteína fundamental en la dieta humana.

La tendencia de conservación ecológica de los "alimentos de alguna parte" se vinculan al valor específico de la producción en regiones y localidades; es el caso de la miel, alimento ancestral ligado a la producción de la milpa en Yucatán y generadora de biodiversidad; por el contrario, la producción de carne conlleva múltiples costos medio ambientales y abastece las cadenas de valor de "alimentos de ninguna parte", es decir, aquellos productos que entran a formar parte de los procesos industriales y manufacturados y pierden la identidad de su origen (Campbell, 2004). Tal es el caso de la soya, producto que, una vez que se convierte en materia prima para el forraje animal, es indistinto de donde provenga. 
Vigente todavía gran parte de la lógica de los regímenes alimentarios anteriores, en el tercer régimen México se adapta a las tendencias mundiales con productos forrajeros, sin embargo, hasta la fecha el país no ha logrado ser autosuficiente en la producción de soya y requiere importar soya transgénica, proveniente principalmente de Estados Unidos. Por ello en 2013 y 2014 se ubicó entre los principales países importadores de soya con 3.65 millones de toneladas (Observatorio de precios, 2014).

Estados Unidos es el mayor productor de soya en el planeta con casi 80 millones de toneladas; le sigue Brasil con cerca de 48 millones de toneladas, otros países productores son Argentina, China e India (FAO, 2015). De acuerdo con Pilson y Prendeville (2004) en Estados Unidos $40 \%$ del maíz, $81 \%$ de la soya y $73 \%$ del algodón han sido trangénicos desde el año 2003, también son trangénicos la canola, la calabaza y la papaya. Otros países productores de transgénicos son Argentina, Canadá, Brasil, China y Sudáfrica.

México no tiene una ubicación significativa en cuanto a la producción de soya a escala mundial, ocupa el lugar número 20, con una producción de apenas 239 mil toneladas en el año 2013 (SIAP-Sagarpa, 2015). Los estados del norte de México son los principales productores, entre ellos Tamaulipas con casi 70 mil toneladas de producción y los estados de Sinaloa, Sonora y Chihuahua. En el sureste está Chiapas con poco más de 20 mil toneladas, así como Campeche y Veracruz con casi 10 mil toneladas. La producción de soya en Yucatán es poco representativa en el país con menos de 4 mil toneladas. Es decir, las autoridades mexicanas se han visto en la necesidad de expandir la frontera de tierras para la producción de soya en el sureste del país con el objetivo de lograr el abasto de forrajes para el mercado interno y dentro de la lógica mundial de las cadenas de valor cereales-carne.

El presente artículo consta de ocho apartados: 1. introducción, 2. marco teórico, 3. antecedentes, 4. discusión, 5. metodología, 6. límites del trabajo y futuras propuestas, 7. resultados de la encuesta a productores de soya y del modelo econométrico, y 8. la última parte contempla una reflexión. 


\section{MARCO TEÓRICO}

En torno a los temas del medio ambiente y ecología existen, conviven, se complementan y también llegan a contraponerse en aspectos relevantes, tres propuestas teóricas con su respectiva visión del mundo contemporáneo (gráfica 1). La primera de ellas es la economía ambiental, sustentada en la economía neoclásica; desde su perspectiva se formula la necesidad del crecimiento económico y se añaden una serie de criterios para calificarlo como sostenible. Para Cuerdo y Ramos (2000) implica mantener el ritmo de consumo y producción a largo plazo. La economía ambiental tiene relación estrecha con el control de las tasas de agotamiento de algunos recursos naturales, así como mediar en la afectación de la contaminación y problemas ambientales producto de la urbanización y la industrialización. Para la economía ambiental, el bienestar humano que genera el crecimiento se coloca en primer orden y se subordina, en segundo plano, a la naturaleza o a las consideraciones ecológicas (Toledo, 2012).

Gráfica 1. Propuestas y enfoques sobre medio ambiente, sustentabilidad y ecología

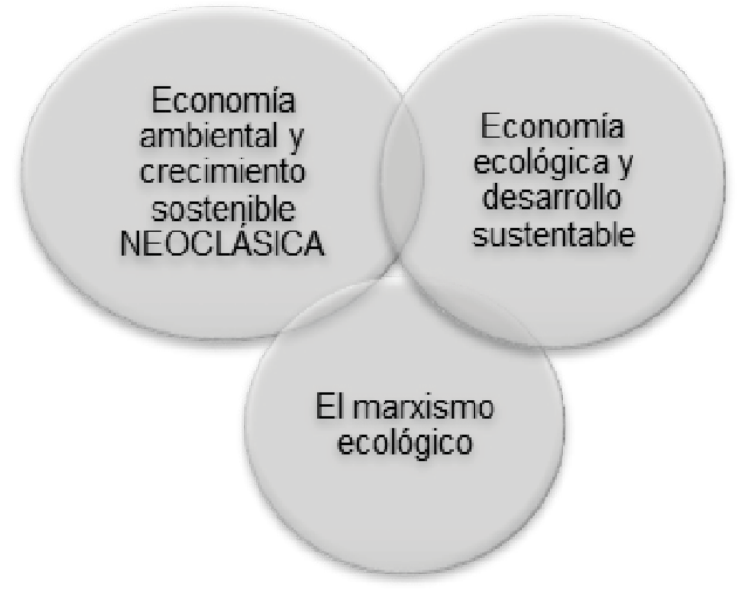

Fuente: Elaboración propia. 
Dentro de las aportaciones más importantes de la economía ambiental para la agricultura se encuentran las externalidades, en esencia son los costos o beneficios que involucran a terceras personas, las cuales no han participado directamente en los procesos de producción. Las externalidades en teoría deberían tener implicaciones en los precios (Cabañes, 2002). Existen externalidades positivas y negativas; en la agricultura pueden observarse ambos tipos. Por el lado de las externalidades negativas, en la agricultura es donde se presentan altos niveles de contaminación difusa. Este tipo de contaminación es característica de la aplicación de agroquímicos al aire libre o los que se van directamente a los mantos acuíferos. Las externalidades negativas por contaminación se relacionan con la instrumentación de impuestos y subsidios, y los cambios sectoriales a que haya lugar; es decir, si un sector agrícola está contaminando habría que aplicar un impuesto, por el contrario, si un sector es bondadoso con el medio ambiente habría que subsidiar. Es el caso de la producción de soya si está contaminando y la miel como conservadora de la biodiversidad. El no tomar en cuenta estos parámetros en las decisiones de política agrícola afecta de manera profunda los ecosistemas y la vida humana.

Normalmente a los productores no se les penaliza por el uso de los agroquímicos y se siguen filtrando de manera cotidiana en los mantos freáticos o se canalizan a la atmosfera aparentemente sin un costo; sin embargo, la contaminación ya ha afectado a terceros con intoxicaciones o enfermedades como el cáncer. La industria de los agroquímicos también evade los costos de las consecuencias adversas de sus productos.

Por otro lado, como externalidad positiva la agricultura es una actividad generadora de agroecosistemas, paisaje y territorio, gran parte de ellos vinculados a los sistemas agrarios tradicionales.

Los precios de los productos agrícolas se enfrentan, por lo tanto, a una distorsión en su costo real y a una falla de mercado, en cuanto a que no internalizan los costos medioambientales. De acuerdo con Torres y Trápaga (2002) con base en la OECD este fenómeno se explica de tres maneras:

a) Una subestimación de los recursos, la intervención estatal genera la idea de abundancia de recursos, b) dificultad para medir el valor económico real de la productividad de los suelos y la biodiversidad, c) no 
se contabilizan las externalidades en el valor de mercado, ya sean positivas o negativas, y protección de los hábitats naturales o la contaminación de aguas o ríos.

Con respecto a la segunda propuesta, a saber, la economía ecológica y el desarrollo sustentable, Borrayo (2002) menciona que la sustentabilidad tiene tres ejes sistémicos; lo ecológico, lo económico y lo social. Lo ecológico tiene múltiples dimensiones, como la limitación de explotación de los recursos naturales y su relación con la capacidad de absorción o degradación en el medio ambiente de los residuos, producto del consumo y de la industrialización. Otros aspectos tienen que ver con la conservación de la biodiversidad, paisaje y territorio.

El control del crecimiento económico es apremiante en virtud de una naturaleza avasallada y un sistema de producción inserto en la restricción de los consumos energéticos (Toledo 2003). Lo sustentable implica que el crecimiento económico reoriente las pautas que existen en términos de consumo y producción por aquéllas que condicionen una mejor integración al medio ambiente. Unido a ello, hay una crítica al concepto de productividad y eficiencia, por aquella que toma como base las propias características de los agroecosistemas y su capacidad de resistencia (Naredo, 2006).

Por último, la limitación y los cambios en los procesos de crecimiento llevan implícita la necesidad de una mayor equidad del ingreso y la inclusión en el bienestar social de los actores que participan en los procesos de producción y consumo.

La sustentabilidad en la agricultura se relaciona con el consenso mundial de nuevas estrategias que aseguren una producción estable de alimentos para alcanzar la seguridad alimentaria, erradicar la pobreza, conservar y proteger el medio ambiente (Altieri y Nicholls, 2000). Las premisas actuales sobre las que se sustenta la agricultura moderna, con procesos artificiales dependientes de energía fósil (petróleo) predominan en los procesos productivos agrícolas y conducen al agotamiento de los recursos naturales como el agua, erosión de los suelos, pérdida de biodiversidad y cambios climáticos. Se origina también la desaparición de la riqueza ancestral cultural, culinaria y de usos, tradiciones y costumbres, de las prácticas de los pueblos originarios de comunidades campesinas con un importante legado ecológico. 
Algunos países que mantienen un alto porcentaje de población campesina son: China, India, Pakistán, Egipto, México, Brasil y Ecuador, entre otros. Altieri y Nicholls (2000) analizan la importancia de la agricultura familiar en pequeña escala, incluso en países industrializados como Estados Unidos; Holanda, Alemania y Bélgica. El caso de Cuba con avances significativos en la agricultura orgánica y ecológica (Toledo, 2003). La importancia de la producción familiar en el mundo se vincula con la capacidad de los pueblos de generar su seguridad alimentaria.

La tercera propuesta es el marxismo ecológico, en donde se cuestionan los procesos de sustentabilidad como paliativos para continuar con la acumulación de capital. El consumo y la producción son los que han determinado la crisis del agotamiento de los recursos naturales, por lo que los cambios estarán relacionados con nuevos patrones de comportamiento social, económico y político de los individuos con respecto a la naturaleza (Altvater, 2005). Dentro de los múltiples elementos de selección entre ecología y economía las aproximaciones insisten en el papel de la segunda ley de la termodinámica, "Ley de la entropía", donde se manifiesta que la energía no solo se transforma sino también se degrada. Con esta degradación cambian, sustancialmente, los parámetros en la calidad de energía que existe en el mundo; lo que conlleva a consecuencias sociales y limita las posibilidades de mantenimiento, en el tiempo, de los procesos de la acumulación de capital. Para superar la crisis serán necesarios cambios profundos en el planeta que impliquen reformular la contradicción entre economía y ecología.

Dentro del marxismo, la teoría de los regímenes alimentarios permite explicar y ubicar no solo las tendencias mundiales en la agricultura y la inserción en ellas de los países, sino ir más allá al explicar la lógica de la hegemonía mundial, y sus repercusiones en todos los ámbitos del planeta.

Lo que debe resaltarse de los regímenes alimentarios con base en Winders (2009) es lo siguiente: primero, el dominio de la política mundial por la hegemonía en turno, cada una con su política nacional con intervención estatal y mecanismos de mercado, con impacto en la producción, consumo y en el comercio mundial agrícola, que incluye las materias primas; segundo, los tratados de libre comercio (TLCAN en México) son parte de esta hegemonía que se propaga; tercero, mientras 
el país hegemónico tiene una importante regulación e intervención gubernamental en su política exterior promueve, por otra parte, el libre mercado para el resto de los países (una isla intervenida por gobierno y un gran océano de libre mercado); cuarto (punto que el autor enfatiza de manera especial), los intereses que se mueven al interior de la producción de alimentos en la agricultura mundial y que responden a determinadas coaliciones preestablecidas desde el centro hegemónico en turno; incluye a clases de poder, mercado y Estado. El autor cita a Polanyi y habla de dos movimientos complementarios y no excluyentes: el primero basado en un régimen de libre mercado y el segundo centrado en un régimen de regulaciones nacionales del gobierno hegemónico. Este doble mecanismo es manejado por el poder político y cambia de acuerdo con los intereses económicos.

\section{ANTECEDENTES}

La producción de soya transgénica se introdujo en su fase experimental en el año $2001^{2}$ en Campeche, estado ubicado en el sureste de México colindante con el deYucatán, lugar donde se introduce la soya transgénica en fase experimental desde el año 2003 y en el año 2008 se otorga permiso a Monsanto Comercial S.A de C.V. para incrementar la superficie a 12,000 hectáreas en Yucatán, municipios de: Santa Elena, Ticul, Oxkutzkab, Tekax, Tzucacab, Peto y Tizimín, e incluye a otros municipios del estado de Campeche (Batllori, 2012).

En el año 2012 se otorga otro permiso de liberación comercial a Monsanto para cultivo de soya transgénica en una superficie de 253,500

\footnotetext{
2 En México, entre 1988 y 2005 el Gobierno Federal por conducto de la Secretaría de Agricultura con el aval vinculante de la Secretaría de Medio Ambiente y Recursos Naturales (SEMARNAT) otorgó 330 permisos de liberación al ambiente de semillas transgénicas. Se otorgaron autorizaciones para pruebas experimentales para papa, tomate, calabacita, maíz, tabaco, trigo, soya, alfalfa, canola, melón, algodón, jitomate, chile, papaya, clavel y limón. Entre 2005 y 2009 se otorgaron 211 permisos de liberación de transgénicos a escala experimental y 20 permisos en fase piloto; ninguno fue comercial. De 2010 a la fecha proliferaron los permisos para pruebas experimentales de algodón, soya y maíz, y se dieron algunos para cultivos piloto. Hasta marzo pasado se otorgaron tres permisos de pruebas piloto (previo a la fase comercial) de maíz a la empresa Monsanto para Durango y Coahuila, y otros tres para Tamaulipas. Para algodón se dieron cuatro autorizaciones para cultivo comercial a la misma empresa, en julio y agosto pasados (La Jornada, 11 de Junio 2012).
} 
hectáreas que incluye a los estados de Campeche, Quintana Roo, Tamaulipas, San Luis Potosí, Veracruz y Chiapas. Algunos de ellos, como el caso de Tamaulipas, son los principales estados productores de soya en el país. La Península de Yucatán se incorporaría con 60,000 hectáreas y un total de 13,075,000 kilogramos de semilla de soya transgénica.

Como ya se hizo mención, el objetivo del permiso del gobierno mexicano para la siembra de soya transgénica en Yucatán era aumentar la cantidad de tierras para su producción y lograr abastecer el mercado local de alimento de forrajes así como la producción de aceite vegetal. Monsanto justificaba este producto agrobiotecnológico como el mejor en control de malezas, mediante el uso del herbicida glifosato, al cual la semilla es resistente (Batllori, 2012). Enseguida se hace mención de la discusión que generó la siembra de soya trangénica en Yucatán.

\section{DISCUSIÓN}

1.- Uno de los principales efectos de la producción de soya transgénica en el estado de Yucatán era el peligro inminente del uso del herbicida glifosato. La soya transgénica MON-04032-6 es tolerante al herbicida que produce la empresa Monsanto con el nombre comercial "Faena", su ingrediente principal es el glifosato. De acuerdo con la Agencia Internacional para la Investigación sobre el Cáncer (IARC, 2015) de la Organización Mundial de la Salud (OMS), el glifosato altera la función hormonal de las celulas en humanos y puede derivar en cáncer, entre otras afectaciones a la flora y fauna de los lugares donde se aplica (Schubert, 2015). El herbicida glifosato se encuentra en la lista de los plaguicidas más peligrosos en el mundo (Pesticide Action Network, PAN, 2015), documento apoyado por la Organización de las Naciones Unidas para la Alimentación y la Agricultura (FAO). El documento hace mención a las regulaciones internacionales del Convenio de Estocolmo, que tiene como objetivo la eliminación de los contaminantes orgánicos persistentes, amenazas mundiales para los seres vivos; y el convenio de Rotterdam, para regular el intercambio de información en el comercio internacional en materia de determinados plaguicidas peligrosos. 
2.- El glifosato es altamente soluble en el agua, el suelo de Yucatán es poroso y permea fácilmente las substancias a los mantos freáticos, el uso de agroquímicos como el herbicida glifosato usado de manera intensiva para la producción de soya transgénica representa un gran peligro para la contaminación difusa en el agua, vida marina y bioidversidad. Se incrementa el riesgo de contaminación en la Peninsula de Yucatán en las zonas de reserva ecológica, en las Biosferas de Ría Celestún, Calakmul, Petenes, Sian ka'an y otras áreas de protección de flora y fauna en estados cercanos como la Laguna de Términos y Bala'an Ka'aax (Batllori, 2012).

3.- La siembra de soya transgénica representa también un peligro para las mieles, hasta el momento se han producido de forma natural en Yucatán, debido a la posible contaminación con polen de cultivos genéticamente modificados. El estado de Yucatán es zona de apiarios, es el primer productor de miel en México con diez mil toneladas de producción anual (SIAP-Sagarpa, 2014). La calidad de la miel en Yucatán hace que sea muy cotizada en los mercados internacionales, más de $80 \%$ de la producción se exporta, principalmente a Alemania y Estados Unidos.

4.- De acuerdo con el Tribunal de la Unión Europea, el polen de organismos genéticamente modificados (OGM) se clasifica como un ingrediente adicional a la miel (Conabio, 2012). Las mieles que estan expuestas a la contaminación mencionada podrían ser afectadas con la disiminución de su precio y/o la cancelación de las ventas a la Unión Europea. La miel de Yucatán tiene el peligro constante de ser contaminada por polen transgénico, como lo demuestran en su trabajo Villanueva, et al (2014). Con base en las muestras que se tomaron para el dignóstico de contaminación de OGM en mieles de Yucatán, algunas de ellas ya contienen la sustancia Glycine max L., correspondiente al polen de soya genéticamente modificada. Se afecta, no solo la biodiversidad de la región sino también las ventas de miel en los mercados internacionales. La inminente posibilidad de contaminación de polen trangénico abarca todo el entorno natural de las plantas silvestres y endémicas, toda vez que los procesos de polinización no tienen fronteras (Schmeiser, 2005; Pilson y Prendeville, 2004). 
7.- La necesidad de limpiar o rasurar las tierras donde se implanta el monocultivo de la producción de soya transgénica vinculadas a todos los cultivos de tipo agro-intensivo provocan la desaparición de selva primaria; condyuvando al cambio climático y al calentamiento global.

8.- Existencia de super-malezas, el uso intensivo de hebicidas genera una resistencia a esos arbustos que se controla normalmente al aumentar la cantidad de su aplicación. "En Estados Unidos el consumo del glifosato pasó de 6.3 millones de libras en 1995 a 41.8 millones en el año 2000..." (Altieri y Pengue, 2005), lo mismo sucede en Argentina y Brasil con la llamada resistencia "múltiple"; este incremento tiene repercusiones en la salud, seres vivos y en el envenenamiento de los mantos acuíferos, debido, como se explicó antes, a que el glifosato es altamente soluble en agua.

Como una respuesta a los efectos que tendría en el entorno natural de Yucatán la producción de soya transgénica aparece el movimiento social con el nombre en lengua maya MA OGM en español: "No a organismos genéticamente modificados". Este movimiento social une a productores de miel, es decir, apicultores de Yucatán y Campeche, comercializadores y empresarios de miel, investigadores, estudiantes, organizaciones no gubernamentales, Green Pace de México y España y sociedad civil, así como al Instituto Nacional de Ecología (INE), la Comisión Nacional de Áreas Naturales y Protegidas (Conanp), la Comisión Nacional para el Conocimiento y uso de la Biodiversidad (Conabio) y a la Secretaría de Desarrollo Urbano y Medio Ambiente de Yucatán (SEDUMA), en conjunto manifiestan su rechazo al uso de la semilla transgénica por los argumentos antes expuestos.

Como resultado de este movimiento social y su organización se logra detener la siembra de soya trangénica. Para el año 2012 el gobierno del estado de Yucatán declara a la entidad como "territorio libre de transgénicos"3. A partir de ese momento se empezarían a sembrar en Yucatán semillas de soya tipo "huasteca" mexicana.

3 "Decreto por el cual se establecen medidas para salvaguardar la salud humana, el medio ambiente, la diversidad biológica, la sanidad animal, vegetal y acuícola y solicitar la emisión de acuerdos de determinación de zonas libres de organismos genéticamente modificados en el territorio del estado de Yucatán" (Diario Oficial del estado de Yucatán, 10 de mayo de 2012). 
Como puede observarse en el cuadro 1, la información para el año 2009, Tekax alcanza casi cuatro mil toneladas de producción, antes no se producía soya en la entidad. Sin embargo, hay una notable disminución para los siguientes años, en especial para 2010 con apenas 899 toneladas y el año 2012 con 1,518 toneladas.

Cuadro 1. Producción de soya en Tekax y Yucatán (toneladas promedio de 2003-2013)

\begin{tabular}{|c|c|c|c|c|c|c|}
\hline SOYA & 2009 & 2010 & 2011 & 2012 & 2013 & Promedio \\
\hline Tekax & $3,318.00$ & 899.5 & $1,499.80$ & $1,518.38$ & $1,441.70$ & $1,735.48$ \\
\hline Yucatán & $3,893.40$ & $1,133.30$ & $2,099.00$ & $1,674.38$ & $2,768.20$ & $2,313.66$ \\
\hline
\end{tabular}

Fuente: SIAP-Sagarpa (2015)

Para el año 2013 la producción de soya en Tekax no logra recuperar sus cifras iniciales y llega a 1,441 toneladas. Yucatán ocupa el noveno lugar en la producción de la oleaginosa en México con solo 1.25\%. Tekax es el principal productor, los otros municipios en importancia son Tizimín con 980 toneladas y Oxkutzcab con 346.5 toneladas, datos para el año 2013 (SIAP-Sagarpa, 2015). Como puede observase, en realidad la producción de soya en Yucatán es poco representativa a escala nacional y cubre parte de las necesidades locales sin lograr abastecer completamente el mercado, lo que hace necesaria su compra en el exterior.

\section{METODOLOGÍA}

El trabajo de investigación incluye encuestas, entrevistas e información de fuentes oficiales como INEGI y SIAP-Sagarpa. Con respecto a las encuestas, la primera se levantó en octubre de 2014 a productores de soya en Tekax, Yucatán. El objetivo principal de la investigación es conocer las condiciones de los productores en términos ambientales, económicos y demográfico-sociales. Se lleva a cabo un análisis por segmentos (programa SPSS) con datos cualitativos y cuantitativos. 
Estudios relacionados con esta investigación son los de Batllori (2012), ${ }^{4}$ Altieri y Pengue (2005), ${ }^{5}$ UCCS y Ecosur (2012). ${ }^{6}$ Otros trabajos relacionados con sustentabilidad son los de Merma y Julca (2012) y Pretty (2008).

Se escogió a los productores de soya del municipio de Tekax porque fue el principal municipio productor de soya transgénica de los años 20082011. A partir del año 2012 es el principal productor de soya "huasteca" nacional.

Los productores del municipio de Tekax, son pequeños y medianos productores con tierras mecanizadas de entre 10 a 70 hectáreas en promedio. El otro municipio productor de soya en Yucatán es Tizimín, el cual tiene grandes empresarios agrícolas, a diferencia de Tekax.

El análisis de la encuesta incluye un diseño de triangulación concurrente, es decir, se recolectan y analizan datos cualitativos y cuantitativos (Hernández, Fernández y Baptista, 2010). En la interpretación se utilizan las dos clases de resultados y se efectúan comparaciones de manera cruzada o de criterio.

Cuadro 2. Indicadores

\begin{tabular}{|c|c|c|}
\hline 1.- Medio-ambientales & 2.- Económicos & 3.- Demográficos y sociales \\
\hline $\begin{array}{l}\text { 1.- Uso de agroquímicos } \\
\text { 2.- Capacitación para el uso de } \\
\text { agroquímicos } \\
\text { 3.- Número de productores } \\
\text { de soya que también son } \\
\text { apicultores y la cercanía de los } \\
\text { apiarios a los cultivos } \\
\text { 4.- Siembra de productos } \\
\text { orgánicos }\end{array}$ & $\begin{array}{l}\text { 1.- Extensión de los predios } \\
\text { 2.- Maquinaria propia } 0 \\
\text { rentada } \\
\text { 3.- Rendimientos } \\
\text { (tonelada/hectárea) } \\
\text { 4.- Convenios, } \\
\text { 5.- Ingresos totales (precios) } \\
\text { 6.- Subsidios }\end{array}$ & $\begin{array}{l}\text { 1.- Edad de los productores } \\
\text { 2.- Años de escolaridad } \\
\text { 3.- Número de hijos } \\
\text { 4.- Nivel educativo de los hijos } \\
\text { 5.-Tipo de actividades } \\
\text { complementarias }\end{array}$ \\
\hline
\end{tabular}

Fuente: Elaboración propia

4 El autor elabora una justificación técnica-científica de las condiciones de siembra de los productores de soya transgénica en Tekax, Yucatán.

5 Llevan a cabo un análisis de las repercusiones de siembra de soya transgénica en Brasil y Argentina.

6 Analizan la imposible coexistencia entre la soya transgénica y la miel en Yucatán. 
Con el objetivo de establecer un valor de muestra en téminos probabilisticos se promedió la cantidad dentro del rango de entre 55 a 70 productores existentes al momento de levantar la encuesta, ${ }^{7}$ lo que arroja un promedio de 62 productores de soya. De acuerdo con Mendenhall, Beaver y Beaver (2012) se aplicó la siguiente fórmula:

$$
\frac{\mathrm{n}=\mathrm{N} * \mathrm{Z}^{2} *\left(\mathrm{p}^{*} \mathrm{q}\right)}{\mathrm{d}^{2}(\mathrm{~N}-1)+\mathrm{Z}^{2} *\left(\mathrm{p}^{*} \mathrm{q}\right)}
$$

Al resolver $n \geq 33$ productores.

El valor representativo mínimo es de 33 productores, la muestra que se levantó corresponde a 38 productores, lo que ubica a la encuesta encima del nivel de significancia de $95 \%$.

Las localidades que se visitaron para el levantamiento de la ecuesta de productores de soya en el municipio de Tekax fueron las siguientes: San Martín Hilí, Benito Juárez, San Pedro Dzulá, Mac-Yan, San Felipe II, Huntochac, Nueva Santa Cruz y Valle del Sur. Con base en las palabras del asesor de la Sagarpa ${ }^{8}$ la encuesta cubrió casi a la totalidad de productores de soya de ese ciclo primavera-verano 2014.

\subsection{Encuesta a los apicultores}

En el mes de junio de 2015 se levantó otra encuesta, en esta ocasión a los apicultores, también en Tekax, Yucatán. Con base en la entrevista con el asesor de la Sagarpa el número total de productores que se diagnosticaron en la zona cercana a los productores de soya fueron entre 150 y 200 productores, por lo tanto, puede tomarse un promedio de 175 productores;

\footnotetext{
7 Cabe resaltar que no todos los productores de la zona producen soya, algunos estaban sembrando maíz y otros, sorgo. Como se depende del temporal de lluvias, del ciclo primavera-verano, los productores tienen que elegir un cultivo. En el caso de los productores que siembran soya o sorgo dejan de producir maíz o lo hacen en menos tierras. Como puede observarse este proceso atenta contra la autosuficiencia alimentaria del maíz. Existen en la zona dos productores de soya de más de 200 hectáreas que tienen tierras de riego y pueden alternar producción en el ciclo otoño-invierno con cultivos de maíz.

8 Sagarpa, Secretaria de Agricultura, Ganadería, Pesca y Alimentación. Institución mexicana creada para resolver problemas del campo y su competitividad. (sagarpa.org.mx), en Tekax tiene representantes en el Centro de Apoyo para el Desarrollo Rural (Cader-Sagarpa-Conafor) lugar donde se levantó la entrevista.
} 
entre ellos hay campesinos de milpa que son también apicultores, así como productores de soya, sorgo y maíz que también tienen apiarios. La encuesta eligió a los que eran apicultores, aunque tuvieran otra actividad y se levantó en las siguientes localidades o comunidades del municipio de Tekax: Ciudad de Tekax Comisaría Ejidal, la localidad de Tixcuytun, las localidades de San Pedro Dzulá, Benito Juárez, Hunto Chac, Nueva Santa Cruz, San Martín Hillí y San Felipe II. Como en la muestra de productores de soya se utilizó la misma fórmula para conocer el tamaño de la muestra probabilística:

Al resolver $n \geq 44$

El tamaño mínimo de la muestra es de 44 productores, la muestra que se levantó incluye a 82 apicultores, muy por encima del nivel de significancia estadística de 95\% (Gujarati y Porter, 2010).

Para conocer el impacto de los cultivos agrointensivos en la producción de miel de Tekax, Yucatán, México, se utiliza un modelo sencillo, de mínimos cuadrados ordinarios con análisis de regresión lineal múltiple con datos transversales (recopilados en un mismo punto del tiempo) de naturaleza no experimental (encuestas de tipo social a productores). El modelo econométrico es el siguiente:

$\mathrm{Yi}=\beta 0+\beta 1 \mathrm{X} 1 \mathrm{i}+\beta 2 \mathrm{X} 2 \mathrm{i}+\mu \mathrm{i}$ donde hay dos parámetros:

$\mathrm{Yi}=$ variable dependiente $=\log$ producción anual de miel $\mathrm{X} 1 \mathrm{i}=$ variable independiente $=$ distancia dummy $=1$ si la distancia $\leq 1000$ metros de los apiarios a los cultivos agrointensivos y; 0 distancia $>$ a 1000 metros.

$\mathrm{X} 2 \mathrm{i}=$ variable independiente $=$ número de colmenas para el productor $\mathrm{i}$

Se utilizó el programa STATA, las pruebas correspondientes se anexan al final del artículo. Los estudios relacionados con el modelo econométrico son: Dogan, Karagoz y Ozbakir (2014), ${ }^{9}$ Lema y Delgado

9. Los autores realizan un estudio para Turquía, con un modelo econométrico para medir la producción de miel. 
$(1998)^{10}$, Hoyle, Hayter y Cresswell (2007), ${ }^{11}$ Morris, Kareiva y Raymer $(1994)^{12}$.

Finalmente se llevaron a cabo entrevistas a funcionarios clave de la Secretaria de Agricultura, Ganadería, Pesca y Alimentación (Sagarpa), Instituto Nacional de Investigaciones Forestales, Agrícolas y Pecuarias (INIFAP) y de la Secretaría de Desarrollo Urbano y Medio Ambiente de Yucatán (SEDUMA), se revisaron fuentes de datos como INEGI, SIAPSagarpa y FAO.

\section{LIMITACIONES Y FUTURAS PROPUESTAS}

1.- Con respecto a la encuesta de productores de soya no se incluyeron algunas variables y datos debido a la existencia del analfabetismo en algunos productores $\mathrm{y}$, en otros casos, a los intérpretes maya-español que no permitieron una mayor confiabilidad en el levantamiento de la información sobre todo de tipo cuantitativo.

2.- El modelo tiene algunas limitaciones, en primer lugar es bastante simplicado y en segundo, se trabaja con datos de un solo periodo, por lo tanto la información puede estar influida por efectos climatológicos o temporales.

3.- El modelo mide el impacto en la cantidad de miel en términos de los cultivos agrointensivos y del número de colmenas, pero no la calidad de la miel, que definitivamente tiene tendencia a cambios significativos.

4.- Un trabajo futuro de investigación tendrá que tomar muestras de miel en series de tiempo de al menos dos años para analizar la calidad de la miel de productores, tanto de milpa como de cultivos agrointensivos.

10 Investigan las fuentes de eficiencia téenica en la producción de miel a partir de una muestra de apicultores del sudoeste de la provincia de Buenos Aires. El estudio utiliza la metodología de frontera paramétricas estocásticas de producción para estudiar los factores que afectan la eficiencia técnica de los productores de miel.

11 Presentan un modelo analítico general para medir como fluyen los genes de polinización cruzada de la canola genéticamente modificada de campo a campo por el viento, abejas y la polinización autónoma. Parametrizan un modelo y la investigación logra predecir que para la polinización de los genes en el caso de la canola transgénica el viento es el principal factor y no las abejas.

12 Llevan a cabo un estudio para establecer estrategias que permitan aislar los cultivos transgénicos de los no-transgénicos y evitar los efectos agronómicos y medio ambientales que los transgénicos generan en las variedades no transgénicas, en términos de cruzamiento fértil en las malezas. 


\section{RESULTADOS}

\subsection{Productores de soya}

\subsubsection{VARIABLES MEDIO AMBIENTALES}

\section{a) Uso de agroquímicos}

La producción de soya tradicional tipo "huasteca" tiene parámetros de contaminación importantes. Los productores encuestados estaban sembrando soya tradicional tipo husteca 200 o $400^{13}$ en el ciclo primaveraverano 2014. La semilla la entrega la Sagarpa y la financia para que los productores la paguen despúes de la cosecha. Todos los productores utilizan para la siembra de esta semilla el fertilizante (fosfato de amonio) y herbicidas con nombres comerciales como Fusiflex, Fulmina y Amina.

En entrevista con un productor:

"En la huasteca utilizamos fosfato de amonio como fertilizante, se utilizan $150 \mathrm{~kg}$ por hectárea, y el herbicida es el Fusiflex, lo vende Syngenta a 860 pesos, [se usa] un litro por hectárea, mezclado en 400 litros de agua, lo aplico con una aspersora Jet, sembré en 100 hectáreas de riego y aparte 70 de temporal. Hace cinco años sembré transgénica en el año 2008-09, usamos también el fertilizante fosfato de amonio y el herbicida Faena del grupo glifosatos, usamos 2 litros por hectárea diluidos en 400 litros de agua, sembramos en tierras de riego 70 hectáreas y el resto lo sembré de maíz".

Solo 12 productores de la muestra manifestaron usar protectores para aplicar los herbicidas, como botas y guantes, el resto, es decir, casi $70 \%$ de lo productores no usan ningún tipo de protector (gráfica 1). En el caso del Fusiflex, de acuerdo con el informe de la empresa Syngenta (2015), es catalogado como medianamente tóxico, por ser soluble puede

13 En entrevista directa con personas del Instituto Nacional de Investigaciones Forestales, Agrícolas y Pecuarias (INIFAP), existen diferentes variedades de semillas de soya tipo "huasteca" que el instituto ha creado, la 100, 200, 3000 400, cuando hacen las pruebas respectivas de rendimientos, tolerancia a plagas, entre otros aspectos, se determina cual es la conveniente para la siembra y es la que entregan a los productores a través de la Sagarpa. 
afectar principalmente aguas subterráneas, es altamente tóxico para microcustáceos y algas, en sus recipientes y almacenamiento debe colocarse el letrero de "Cuidado Veneno", debe usarse protección para su aplicación como cubrebocas, guantes y botas, en las áreas que han sido tratadas con el herbicida se debe evitar que pasen personas, los efectos de sus componentes por intoxicación en personas son mareos, vómitos, dificultad respitatoria, sudor excesivo, transtornos intestinales y estomacales severos, entre otros, puede conducir a coma o muerte y es positivamente cancerígeno para humanos.

Gráfica 1. Protección para aplicar agroquímicos

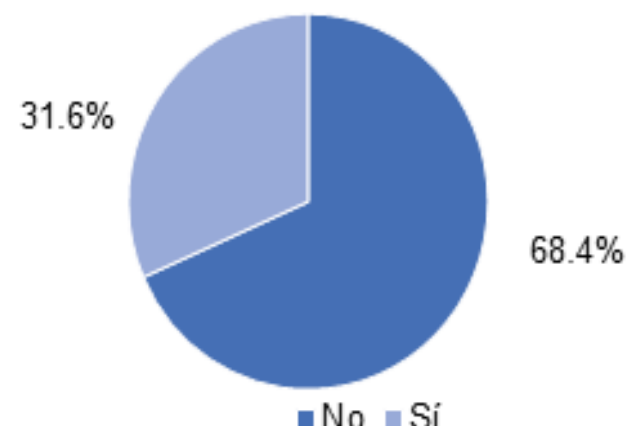

Fuente: Elaboración propia con datos de la encuesta a productores de soya en Tekax, Yucatán, México, en octubre de 2014.

El Fusiflex al igual que el glifosato aparece en la lista de plaguicidas altamente peligrosos (PAN, 2015) el ingrediente activo del Fusiflex es el el Fluazifop-butly en el grupo 2 con efectos a largo plazo (UE SGA tóxico reproducción $1 \mathrm{~A}$ y $1 \mathrm{~B}$ ). "Se sabe o se supone que son tóxicos para la reproducción humana, según el Reglamento 1272/2008/EC de la UE y SGA" (PAN: 28). En general, puede decirse que la producción de soya, ya sea transgénica o nacional "huasteca", utilizan para su producción agroquímicos que tienen efectos importantes en la salud humana y en el medio ambiente. 


\section{b) Capacitacion para el uso de agroquímicos}

Con respecto a la capacitación, 62\% los productores manifestaron la presencia de técnicos para conocer el uso del herbicida y para las condiciones de la siembra de soya. Existen en la zona técnicos capacitados por parte de la Sagarpa que además se encargan de vigilar la región. Algunos productores mencionaron también la presencia de técnicos de la empresa Monsanto.

Gráfica 2. Productores de soya que son apicultores

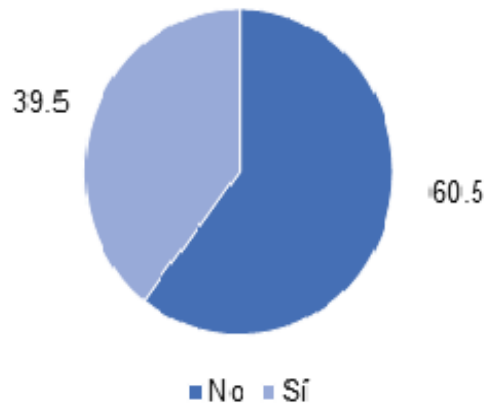

Fuente: Elaboración propia con datos de la encuesta a productores de soya en Tekax, Yucatán, México en octubre de 2014.

c) Productores de soya y apicultores. Cercanía de los cultivos con respecto a los apiarios

Existe una importante relación entre los productores de soya y los producctores de miel; casi $40 \%$ de los productores de soya son también apicultores, lo que muestra la vinculación tan estrecha entre estas dos actividades en Tekax y, en general, en Yucatán (gráfica 2). Aunque algunos de ellos externaron que sus apiarios estaban a 10,50 o 300 metros y otros a 8 kilómetros de distancia de los cultivos de soya, el promedio de la distancia de los productores de la muestra con respecto a sus apiariarios es de 600 metros de los cultivos de soya. Según UCCS y Ecosur (2012) las abejas pueden pecorear en un radio de uno o hasta tres kilómetros en 
periodo de escasez de néctar. En otro trabajo, Ahrent y Caviness (1994), comprueban que los sembradíos de soya son visitados y polinizados por las abejas.

Como ya se ha mencionado, en ausencia de la producción de soya transgénica el trabajo pone énfasis en el análisis del impacto del cultivo de soya tradicional "huasteca". Para este tipo de semilla se usa fumigación del herbicida a cielo abierto, el peligro de contaminación en la miel es muy grande debido a que los campos de sembradío se encuentran cerca de los apiarios.

Queda una incógnita por resolver con respecto al uso del herbicida, algunos productores de soya (menos de 20\%) manifestaron usar el glifosato o Faena, que es el compañero de la soya transgénica. Este herbicida por sus propias características no puede ser usado en la soya tradicional huasteca, se intuye que existe la posibilidad de que algunos productores sigan sembrando semilla de soya transgénica, aunque no lo reconocían abiertamente porque en teoría la siembra de soya transgénica está prohibida en Yucatán.

\section{d) Producción orgánica}

Existe la pervivencia de cultivos tradicionales orgánicos como calabaza y cilantro; frutas como sandía, mamey, guanabana etc, que normalmente son productos relacionados con la milpa, pero que también siembran los productores de soya. Solo siete productores de la muestra (18\%) mantienen estos cultivos, los demás, es decir, $80 \%$ de los productores están apegados a los monocultivos, que pueden ser de soya, maíz o sorgo.

En palabras de un productor de soya:

"Aunque no siembro productos orgánicos me gustaría hacerlo, porque es el futuro, ahora están usando la "mucuna" planta de las leguminosas para mejorar la estructura del suelo, es fijadora de nitrógeno y es parte de un programa orgánico. Es un programa que tiene la Sagarpa, pero no nos informan.

Hay una sistema que arranca las hierbas sin químico. La soya se puede hacer soya orgánica, el problema es quitar la maleza, 
el reto sería como combatir esa maleza, se puede hacer si se programa. Si Sagarpa me pide soya orgánica yo la puedo programar, y prodría ir comiendo esa maleza con mis tractores sin usar herbicida".

Veinticinco encuestados respondieron que les interesaba sembrar productos agrícolas sin contaminantes, sin embargo, no tienen la capacitación para hacerlo y cuando lo hacen les incrementa su costo porque los productos como los fertilizantes orgánicos son más caros en el mercado y muchas veces se pierde el cultivo. No obstante, recalcaron lo importante que era no contaminar.

\subsubsection{VARIABLES ECONÓMICAS}

Las variables que presentan mayor certeza ${ }^{14}$ fueron: extensión de los predios, maquinaria propia o rentada, rendimientos (tonelada/hectárea), convenios, ingresos totales y subsidios.

a) Extensión de predios

Gráfica 3. Extensión de predios de los productores de soya

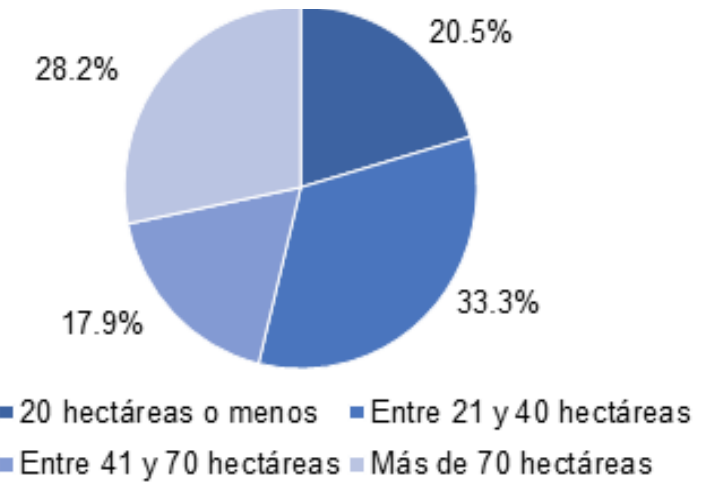

Fuente: Elaboración propia con datos de la encuesta a productores de soya en Tekax, Yucatán, México en octubre de 2014.

14 Aunque la encuesta tiene parámetros de costos y otras variables como las cantidades para el uso de los fertilizantes y herbicidas. Las respuestas presentan serios sesgos, ya sea por el analfabetismo, productores maya-hablantes 0 en algunos casos la falta de capacitación. 
Como antecedente es importante mencionar que gran parte de los productores en Yucatán, es decir, 95\% tienen menos de cinco hectáreas, campesinos minifundistas fundamentalmente de milpa (INEGI, 2014-2). No obstante, en la encuesta de productores de soya en Tekax, la mitad de los productores tienen entre 20 y 70 hectáreas, esto es, son productores medianos (gráfica 3). Hay también un núcleo de productores pequeños de menos de 20 hectáreas. Se identificaron además dos grandes productores con mas de 200 hectáreas de riego. A excepción de estos dos productores, el resto de productores tienen solamente tierras de temporal.

\section{b) Maquinaria propia o rentada}

De igual manera, y a diferencia de gran parte de los campesinos minifundistas del estado de Yucatán, en Tekax los productores de soya trabajan tierras mecanizadas. En tiempos anteriores Tekax había sido una importante región en la producción de caña de azúcar y más tarde de maíz. El municipio está dotado de tierras rojas profundas llamadas en maya "kancab", tierras no pedregrosas excelentes para el cultivo, una importante diferencia con respecto a los suelos pedregrosos que dominan gran parte del territorio en Yucatán (gobierno de Yucatán, 2015-4).

En la encuesta $76 \%$ de los productores tienen maquinaria propia, el resto utilizan maquinaria rentada, lo que significa que todos tienen mecanizadas sus tierras. Algunos expresaron que la maquinaria la habían comprado entre varios de ellos, normalmente son familiares y la comparten entre todos. La maquinaria que usan son: tractores, fumigadoras, sembradoras, cosechadoras y trilladoras. Los años de actualización de la maquinaria varían, en algunos productores la maquinaria tiene más de 30 años. Sin embargo, más de la mitad de los productores, $54 \%$ de la muestra, mencionaron que su maquinaria es de 2003 a la fecha.

\section{c) Rendimientos}

Con respecto a los niveles de rendimiento (toneladas/hectárea), en la gráfica 4 se observa que el promedio de la muestra fue de 1.53 ton/ha. Dos 
productores que tienen 200 ha. con producción de soya huasteca obtuvieron un rendimiento de 2.5 ton/ha, cabe señalar que estos productores tienen sistema de riego, a diferencia del resto de los productores con tierras de temporal. En términos comparativos, el rendimiento promedio en Yucatán en 2014 fue de 1.4 ton/ha y la media nacional, para el mismo año, fue de 1.60 ton/ha (SIAP-Sagarpa, 2015).

Figura 4. Rendimiento de productores de soya, Tekax

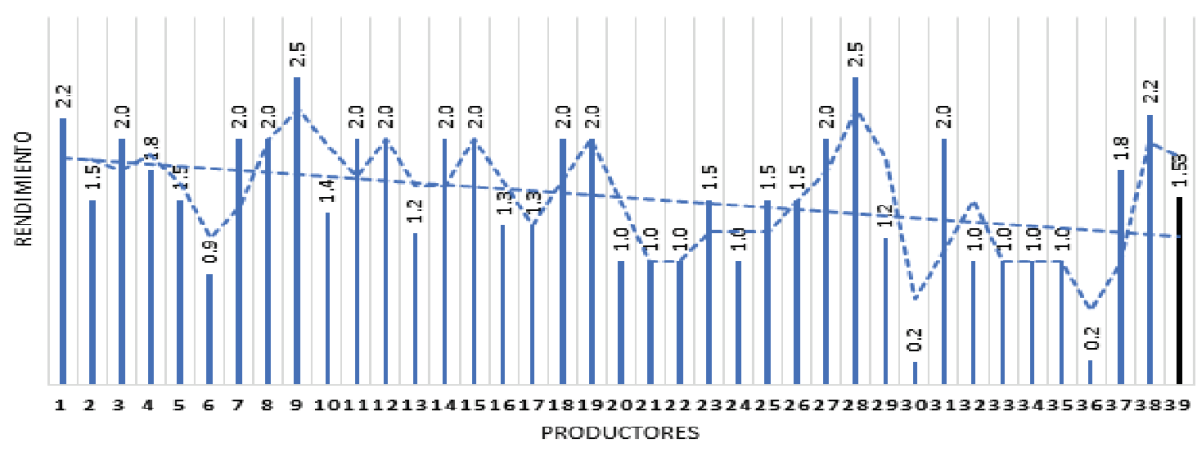

Fuente: Elaboración propia con la encuesta levantada a productores de soya en el municipio de Tekax, Yucatán, México en octubre de 2014.

Según la FAO (2015) los rendimientos promedio de la semilla en los años 1993-2013, en Estados Unidos y Brasil fueron, respectivamente, de 2.67 ton/ha. y 2.53 ton/ha. Lo que quiere decir que los dos productores de Tekax que tienen riego están por encima de la media nacional y mantienen casi el mismo nivel de rendimientos de países como los mencionados. Solo que, a diferencia de ellos, la semilla que se utiliza es tipo huasteca mexicana y no transgénica. Por lo anterior, puede deducirse que los rendimientos están más en relación con las condiciones de producción, como la existencia de riego y la cantidad de extensión de tierras, que con el tipo de semilla que se use.

La capacidad de los productores para poder sembrar de manera alterna en los dos ciclos productivos del año, es decir, en el periodo de lluvias que corresponde a primavera-verano y otro ciclo en otoño-invierno que necesita riego, no pueden hacerlo $90 \%$ de los productores, en virtud 
de que no tienen sistema de riego. De los productores de la muestra $67 \%$ externaron hacer alternancia anual, esto es, cada ciclo primavera-verano en las tierras de temporal. Dichos cultivos pueden ser de soya, sorgo o maíz, en realidad todos los productores mantienen una determinda producción de maíz cada año, parte de ella la autoconsumen y otra la venden. Tekax no solo es el principal productor de soya, sino el principal productor de maíz en Yucatán (SIAP-Sagarpa, 2015). El número de hectáreas de la siembra de soya y maíz ocupan una superficie similar en la región.

No obstante, de acuerdo con las necesidades del país tanto de producción de maíz como de soya, lo ideal sería sembrar soya en el ciclo primavera-verano y maíz en el ciclo otoño-invierno, al dotar de sistema de riego a los productores. La soya deja un fertilizante inicial en la tierra que podría ser utilizado de manera natural para la siembra de maíz, se tendría producción de soya y maíz en el mismo año. Lo que ayuda, por un lado, a la autosuficiencia alimentaria de maíz y, por el otro, a cubrir las necesidades de abasto de soya como forraje. Sin embargo, lo que actualmente sucede es que se deja de producir maíz para producir soya o sorgo.

\section{d) Convenios}

Con respecto a los convenios de compra que permiten al productor tener segura la venta de su producto, la gran mayoría, más de $90 \%$ de los productores de soya los tienen. El resto tienen que buscar donde vender. Los principales convenios que tienen los productores comprenden dos grandes empresas, por una parte, la unica hidrogenadora del lugar Proteina y oleicos, que produce aceite, y la empresa Crío, que produce huevo y carne de pollo. También se le vende a ganaderos particulares.

\section{e) Ingresos totales y subsidios}

En la gráfica 5 puede observarse que casi $70 \%$ de los productores obtienen ingresos que van de los 7,500 a los 15,000 pesos anuales por la venta de soya. A este total habría que agregar el subsidio otorgado por el gobierno de 1,500 pesos por hectárea del Programa pro-oleaginosas; solo $10 \%$ de 
los productores tienen ingresos que superan los 70,000 pesos anuales. Por lo tanto, el cultivo de la soya, no solo no es dominante en Tekax, sino que tampoco es una gran fuente de ingresos. Genera ingresos relativamente importantes únicamente si se considera en relación con la superficie plantada y con los subsidios otorgados.

Gráfica 5. Ingresos totales por segmentos de los productores de soya

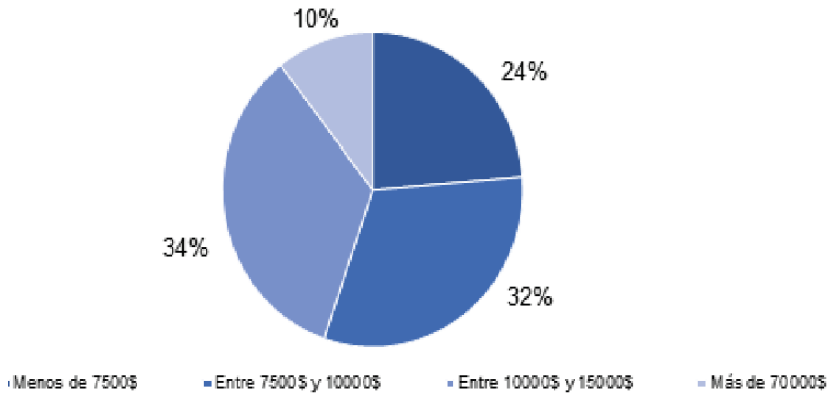

Fuente: Elaboración propia con datos de la encuesta a productores de soya en Tekax, Yucatán, México en octubre del año 2014.

Respecto a los precios de venta, aunque este se establece en la Bolsa de Chicago y en ese año era de 6,500 pesos la tonelada, con base en la encuesta no todos habían vendido a ese precio. Podría haber sido por desconocimiento o por los sesgos que se mencionaron al principio, lo que impidió un precio uniforme. El resultado fue que más de $40 \%$ de los productores vendieron a un precio inferior al indicado.

\subsubsection{VARIABLES DEMOGRÁFICAS Y SOCIALES}

\section{a) Edad de los productores}

En la gráfica 6, la edad promedio de los productores de soya encuestados es de 47 años, casi $70 \%$ son productores que se encuentran en edad madura y productiva, entre 20 y 45 años de edad, a diferencia de otras actividades en Yucatán, como el henequén, donde los productores rebasan los 65 años 
(Rivera y Quintal, 2015). Los productores de soya son una población potencial para la producción de actividades agrícolas.

Gráfica 6. Edad por segmentos de productores de soya

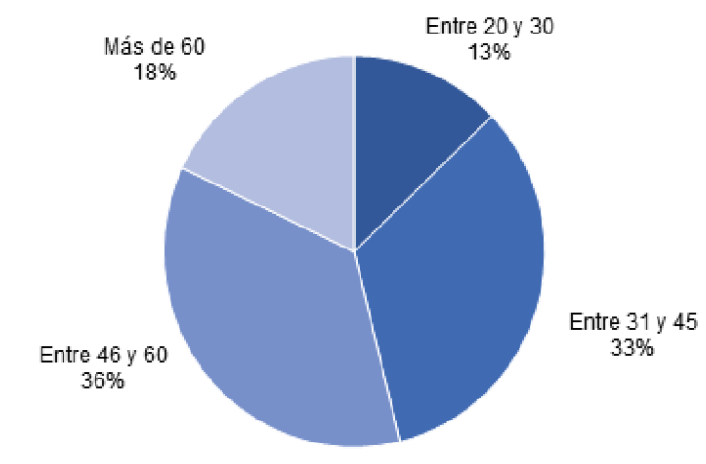

-Entre 20 y $30 \quad$ Entre 31 y $45 \quad$ Entre 46 y $60 \quad$ Más de 60

Fuente: Elaboración propia con datos de la encuesta a productores de soya en Tekax, Yucatán, México en octubre del año 2014.

b) Número de hijos, años de escolaridad y actividades complementarias

El número promedio de hijos son cuatro, el nivel promedio en escolaridad del productor son seis años de estudio, es decir, la primaria, en algunos casos los que tienen menos de 4 años de estudio apenas podían leer y escribir, en otros, los menos, son analfabetas (gráfica 7). Se encontraron también dos productores que eran agrónomos de profesión. Cuando se levantó la encuesta algunos de los productores hablaban lengua maya y fue necesario que un traductor o sus hijos bilingües (maya-español) proporcionaran la información. 


\section{Gráfica 7. Años de escolaridad}

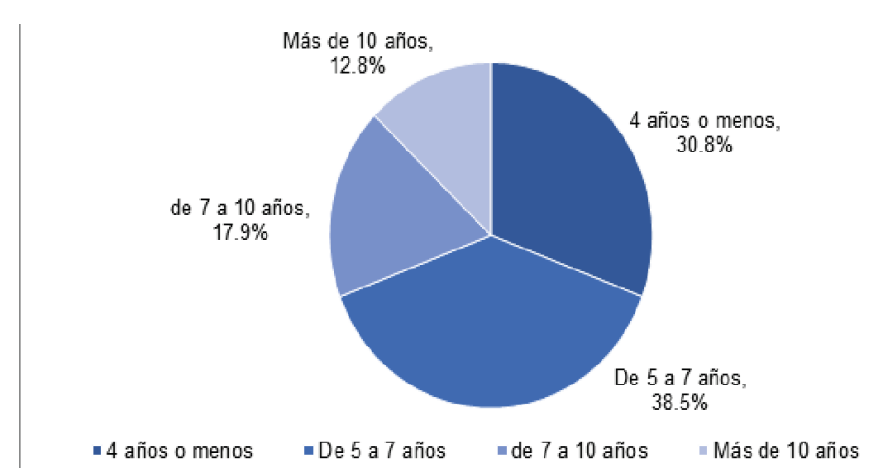

Fuente: Elaboración propia con datos de la encuesta a productores de soya en Tekax, Yucatán, México en octubre del año 2014.

La gran mayoría de los hijos de los productores fueron a la escuela, con niveles de primaria y secundaria, solo cinco productores tenían hijos con educación superior: turismo, administración de empresas, contador público, enfermería y derecho. Los productores de soya en Tekax se dedican a producir, es decir, no tienen actividades complemantarias; en el caso de los hijos también son agricultores, pero señalaron trabajabar como taxistas, obreros, comerciantes, corte y confección y construcción; solo uno de los productores de la encuesta dijo que su hijo era migrante y trabaja en Estados Unidos.

\subsection{Resultados del modelo econométrico, encuesta a apicultores}

El impacto que tienen los cultivos agro-intensivos en la producción de miel fueron los siguientes:

a) E1 0.52 correspondiente al coeficiente $\beta 1$ implica que la producción de miel aumenta en promedio $52 \%$ para los productores de miel que están a $<$ de 1000 metros de distancia de los cultivos agro-intensivos;

b) Con respecto a $\beta_{2}$ la producción de miel aumenta dos por ciento en promedio por cada colmena adicional que los apicultores tengan. Por tanto: 


$$
\mathrm{Y}_{\mathrm{i}}=5.39+(0.52) \mathrm{X}_{2 \mathrm{i}}+(0.02) \mathrm{X}_{3 \mathrm{i}}+\mu_{\mathrm{i}}
$$

\begin{tabular}{r|rrrrrr}
\hline logproduccina 1 & Coef. & Std. Err. & $t$ & p $>|t|$ & [958 Conf. Interval] \\
\hline distancidummy & .5299496 & .2483126 & 2.13 & 0.036 & .0356958 & 1.024204 \\
nmerodecolmenas & .0201923 & .0029585 & 6.83 & 0.000 & .0143037 & .026081 \\
_cons & 5.396779 & .2080409 & 25.94 & 0.000 & 4.982684 & 5.810874 \\
\hline
\end{tabular}

El primer hallazgo del modelo es que los coeficientes pueden variar. Para un cálculo más preciso, debido a que existe un error de aproximación al emplear logaritmo en la variable dependiente sin haber logaritmo en las variables independientes, es necesario hacer la aproximación con base en Wooldridge (2010) con un valor para (e=2.718281828):

Con respecto a la corrección en la variable independiente dummy (distancia de los cultivos agrointensivos a los apiarios):

$\Delta$ producción $=100\left[\mathrm{e}^{0.5299}-1\right]=69.87 \%$

Con respecto a la corrección de variable número de colmenas:

$\Delta$ producción $=100\left[\mathrm{e}^{0.0201}-1\right]=22.2 \%$

Los productores que están a menos de 1000 metros de los cultivos agro-intensivos aumentan su producción de miel en $69.87 \%$.

El coeficiente del número de colmenas se incrementa a $22 \%$, es decir la producción de miel aumenta en ese porcentaje por cada colmena adicional que tienen los apicultores. Entonces los nuevos coeficientes son:

$\log$ producción anual de miel $=5.39+0.6987($ distancia $d u m m y)+$ 0.222 (número de colmenas) $+\mu_{\mathrm{i}}$

La regresión comprueba la hipótesis nula, lo que significa que los cultivos agro-intensivos tienen un impacto positivo en la producción de miel ¿A qué puede deberse este proceso, cuando en teoría los cultivos agro-intensivos tendrían que tener un papel más que secundario?

\section{JUSTIFICACIÓN}

En primer lugar se logró diagnosticar que 50\% de los apicultores de la encuesta mantienen entre 30 y 100 colmenas en sus apiarios. Cabe 
resaltar que es mucho más redituable producir miel para la venta, que otros productos de la milpa, como es el caso del maíz, alimento que se produce en gran medida para autoconsumo y que no tiene precio de garantía.

De acuerdo con Villanueva (1990) la media del número de colmenas para mantener un equilibrio en la producción de miel es de 25 colmenas por productor, al existir más colmenas en áreas cercanas tiende a romperse con un equilibrio del monte o monte alto, donde las abejas toman el néctar. Por lo tanto, al incrementarse el número de colmenas existentes las abejas buscarán en lugares más lejanos el néctar. Si los cultivos agro-intensivos se encuentran a menos de 1000 metros como ya se ha analizado, no es raro entonces que cumplan esa función.

Otro rasgo importante es la cantidad de incendios y tierras deforestadas que han terminado con gran parte de árboles y flores endémicas productoras de miel. Ahora los cultivos que se mantienen verdes, incluso en época de secas, son los cultivos agro-intensivos debido a la utilización de riego.

El sistema roza-tumba-quema había sido un sistema sustentable cuando los periodos de descanso de las tierras oscilaban entre 25-30 años o más. No obstante, actualmente los periodos han disminuido hasta 5 o 10 años, incluso menos (Terán y Rasmussen, 2009). Primero, porque cada vez los campesinos milperos tienen menos tierra y segundo hay un aumento de tierras dedicadas a los cultivos de tipo agro-intensivo. Este proceso acelera la tala de árboles importantes para la producción de miel y la deforestación, así como la necesidad del uso de agroquímicos, incluso al interior de la milpa.

Como se explicó antes, el presente estudio analiza el impacto de los cultivos agro-intensivos en la producción de miel, no obstante, debido a la importante repercusión que se presenta con la presencia de dichos cultivos, los peligros de contaminación en la miel son mayores. El seguimiento es un estudio que analice pruebas en la calidad de la miel.

\section{REFLEXIÓN FINAL}

Sin duda alguna hay un gran avance en el hecho de que no se siembre soya transgénica en Tekax, Yucatán, los peligros que se analizaron en la sección 
anterior podrían ser superados. Sin embargo, las condiciones en las que se lleva a cabo la producción de soya huasteca permiten diagnosticar que están presentes importantes procesos de contaminación. Aunque gran parte de los productores tienen o tuvieron capacitación para el uso de los agroquímicos, queda el peligro inminente de la falta de protección en el uso de plaguicidas-herbicidas y la contaminación que se canaliza a los mantos freáticos, así como la afectación constante en la biodiversidad a través del uso de plaguicidas a cielo abierto.

Relacionado íntimamente con estos procesos de contaminación está la producción de miel. Según los resultados, más de la mitad de su producción esta correlacionada positivamente con los cultivos agrointensivos existentes en la zona de estudio. Aspectos como la producción intensiva de miel, la erosión y los incendios, los cambios en la biodiversidad y hasta el sistema tumba-roza y quema, se relacionan con dichos resultados.

La necesidad de producir soya en México conlleva a la toma de decisiones en la política agropecuaria, para extender e intensificar su producción en lugares como Tekax, Yucatán. No obstante, la cuestión no es si se produce soya o no, sino que las semillas que se utilizan, transgénicas o tipo huasteca, necesiten agroquímicos tan peligrosos para su siembra. En palabras de un productor, "el mercado de los orgánicos es el futuro y la siembra de soya orgánica es posible, todo depende de que las instituciones mexicanas den las señales adecuadas para hacerlo". En entrevista con investigadores del INIFAP sería posible hacer una semilla de soya que no use agroquímicos, siempre y cuando se invierta en investigación y desarrollo para lograrlo. Cabe señalar el impacto positivo en materia de sustentabilidad que tendría la producción de soya orgánica con tendencias globales a favor de la agroecología y del valor de los "alimentos de alguna parte”, identificados por su calidad orgánica y ecológica.

El otro hecho diagnosticado es la necesidad de sembrar en los dos ciclos del año, es decir, en primavera-verano con lluvias de temporal y en el ciclo otoño-invierno que necesita riego. La siembra de soya deja un fertilizante inicial que podría utilizarse para la siembra de maíz. Todo depende que a los productores mecanizados de Tekax se les dote de sistemas de riego para que puedan hacer los dos cultivos anualmente. 
La siembra de maíz tiene que ver con la autosuficiencia alimentaria para cubrir la dieta de los mexicanos. Pero no se puede demeritar la importancia de cultivo de soya para la producción de carne, alimento que los mexicanos también llevan a sus mesas, como una importante fuente de proteína.

\section{REFERENCIAS}

Ahrent, D.K. y C.E. Caviness. 1994. Natural cross-pollination of twelve soybean cultivars in Arkansas, Crop Science, 34(2): 376-378.

Altieri, M. y C.I. Nicholl. 2000. Teoría y práctica para una agricultura sustentable, Serie textos básicos para la formación ambiental, PNUMA, Red de formación ambiental para América Latina y el Caribe, México.

Altieri M. y W. Pengue. 2005. La soja transgénica en América Latina, consultado el 14 de mayo de 2015 en www.ecoportal.net

Altvater E. 2005. Hacia una crítica ecológica de la economía política, primera y segunda parte, Mundo Siglo XXI, www.politicas.posgrado. unam.mx

Batllori, E. 2012. Justificación técnica-científica para emitir opinión favorable a solicitudes de zonas libres de cultivos de organismos genéticamente modificados en el estado de Yucatán, Secretaría de Desarrollo Humano y Medio Ambiente, consultado el 2 de abril de 2015 en http://www.seduma.yucatan.gob.mx/apicultura_transgenicos/documentos/JUSTIFICACION_TECNICA_CIENTIFICA_OGMS.pdf

Borrayo López, R. 2002. Sustentabilidad y desarrollo económico, Mc Graw-Hill.

Cabañes, Ma. Lucía (Comp.). 2002. Microeconomía esencial, Ariel Economía.

Campbell, H. 2004. Breaking new ground in food regime theory: corporate environmentalism, ecological feedbacks and the "food from somewhere" regime? Agri Hum Values, 26: 309-319.

Conabio. 2012. Análisis de riesgo sol 007/2012. Consultado el 20 de mayo de 2012 en http://www.biodiversidad.gob.mx/genes/evaluacionRiesgo.html 
Cuerdo, M. y J. Ramos. 2000. Economía y naturaleza, una historia de las ideas, Síntesis, Madrid.

Diario Oficial del estado de Yucatán. 10 de mayo de 2012. Decreto núm. 525, consultado el 22 de marzo de 2012 en http://www.yucatan.gob. $\mathrm{mx} /$ servicios/diario_oficial/? $\mathrm{f}=2012-05-10$

Dogan, Z, M. Karagoz y G. Ozbakir. 2014. Long years apiculture data model of Turkey: Econometric time series analysis, The Journal of Animal \& Plant Sciences, 24(5): 1573-1578.

FAO. 2015. Food and Agriculture of the United Nation, consultado el 15 de mayo de 2015 en http://data.fao.org/dataset-datafilter?entryId=e0135469-a041-45aa-a1a7-7b9c775da78c\&tab=data

Gobierno de Yucatán, 2015-4. Ordenamiento ecológico territorial del estado de Yucatán, consultado el 11 de marzo de 2015 en http://www. bitacoraordenamiento.yucatan.gob.mx/archivos/200701102549.jpg

Gujarati, D. y D. Porter. 2010. Econometría, 5a edición, McGrawHill.

Hernández Sampieri, R., C. Fernández y P. Baptista. 2010. Metodología de la investigación, $5^{\text {a }}$. edición, J. Mares Chacón, México.

Hoyle, M., K. Hayter y J. Cresswell. 2007. Effect of pollinator abundance on self-fertilization and gene flow: Application to GM Canola, Ecological Applications, 17(7): 2123-2135.

IARC. 2015. Carcinogenicity of tetrachlorvinphos, parathion, malathion, diazinon, and glyphosate, The Lancet Oncology, 16(5): 490-491, consultado el 30 de marzo de 2016 enhttp://www.reduas.com.ar/wpcontent/uploads/downloads/2015/03/Glifosato-Informe-IARC-1.pdf

INEGI. 2014-2. Censo agrícola ganadero y forestal 2007, consultado el 10 de octubre en http://www3.inegi.org.mx/sistemas/tabuladosbasicos/ default.aspx?c $=17177 \& \mathrm{~s}=$ est

La Jornada. 12 de junio de 2012. Miel y transgénicos, ¿La imposible coexistencia? consultado el 21 de diciembre de 2013 en http://www. jornada.unam.mx/2012/06/12/opinion/020a2pol

Lema, D., y Delgado, G. 1998. Productividad y fuentes de eficiencia técnica en apicultura: estimación de fronteras estocásticas de producción con datos de panel, Instituto de Economía y Sociología-INTA, 22. 
McMichael, P. 2009a. A food regime genealogy, The Journal of Peasant Studies, 36(1): 139-169.

2009b. Banking on agriculture: A review of the World Development Report 2008, Journal of Agrarian Change, 9(2): 235-246.

Mendenhall, W., Beaver, R., y Beaver, B. 2012. Introducción a la probabilidad y estadística, Décima Tercera Edición, Cengage Learning.

Merma, I. y A. Julca. 2012. Caracterización y evaluación de la sustentabilidad de fincas en Alto Urubamba, Cusco, Perú, Ecología Aplicada, 11(1): 1-11.

Morris, W., P. Kareiva y P. Raymer. 1994. Do barren zones and pollen traps reduce gene escape from transgenic crops? Ecological Applications, 4(1): 157-165.

Naredo, J.M. 2006. Raíces económicas del deterioro ecológico y social. Más allá de los dogmas, Siglo XXI.

Observatorio de precios. 2014. Al servicio de productores y consumidores de alimentos, consultado el 19 de marzo de 2016 en http://observatoriodeprecios.com.mx/index.php/precios-productos/productos-agropecuarios/soya/454-la-semilla-de-soya-es-el-principal-producto-deimportacion-del-sector-agropecuario

Pesticide Action Network. PAN. 2015. International list of highly hazardous pesticides, Hamburgo, Alemania.

Pilson, D. y H. Prendeville. 2004. Ecological effects of transgenic crops and the escape of transgenes into wild populations, Annual Review of Ecology, Evolution, and Systematics, 35: 149-174.

Pretty, J. 2008. Agricultural sustainability: Concepts, principles and evidence. Philosophical Transactions of the Royal Society B, Biological Sciences, 363(1491): 447-465.

Rivera, A. y A. Quintal. 2015. Política agrícola sustentable e inclusión de los campesinos. Henequeneros y apicultores de Yucatán, en A. Rivera de la Rosa (comp.) Políticas públicas para la inclusión social. Énfasis en estudios para Yucatán, Universidad Autónoma de Yucatán.

Schmeiser, P. 2005. Derechos: productores contra trasnacionales, en A. Bartra et al. Transgénicos ¿Quién los necesita?, Grupo Parlamentario del PRD en la LIX Legislatura de la Cámara de Diputados del Congreso de la Unión, México. 
Schubert, D. 2015. Se avecina un desastre alimentario. Informe sobre agrotóxicos y transgénicos. Consultado el 10 de marzo de 2015 en http:// www.ecoportal.net/Temas_Especiales/Transgenicos/Se-avecina-undesastre-alimentario-Informe-sobre-agrotoxicos-y-transgenicos

SIAP-Sagarpa. 2014. Sistema de información agropecuaria y pesquera,

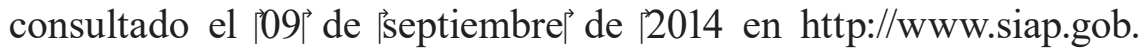
$\mathrm{mx} /$ cierre-de-la-produccion-agricola-por-cultivo/ y http://www.siap. gob.mx/ganaderia-resumen-estatal-pecuario/

SIAP-Sagarpa 2015. Sistema de información agropecuaria y pesquera, consultado el 01 de junio de 2015 en http://www.siap.gob.mx/cierrede-la-produccion-agricola-por-estado.

Syngenta, 2015. Fusilade Max, consultado el 17 de enero de 2017 en https:// www.syngenta.es/product/crop-protection/herbicida/fusilade-max

Swanson N., A. Leu, J. Abrahamson y B. Wallet. 2014. Genetically engineered crops, gliphosate and the deterioration of health in the United States of America, Journal of Organic Systems, 9(2): 6-37, consultado el 11 de abril, 2016 en www.uccs.mx

Terán, S. y C. Rasmussen. 2009. La milpa de los mayas, 2ª edición, UNAM, México, Centro Peninsular en Humanidades y Ciencias Sociales y Universidad de Oriente.

Toledo, M.V. 2003. Ecología, espiritualidad y conocimiento, de la sociedad del riesgo a la sociedad sustentable, PNUMA Universidad Iberoamericana.

- M.V. 2012. Conferencia magistral, Foro sobre los grandes problemas nacionales, diálogos sobre la regeneración de México, consultado el 22 de julio de 2014 en https://www.youtube.com/watch?v=C51cUezoy9c

Torres, F. y Y. Trápaga. 2002. La agricultura orgánica, UNAM/Plaza y Valdés.

UCCS y Ecosur. 2012. Miel y cultivos transgénicos en México: la imposible coexistencia, Escrito que en calidad de Amicus Curiae presentan al Juzgado Segundo de Distrito del Trigésimo Primer Circuito, consultado el 30 de enero de 2015 en: www.uccs.mx

Villanueva, E. 1990. La formación de las regiones en la agricultura, Maldonado Editores, INI/FCA-UADY/CEDRAC. 
Villanueva-Gutiérrez, R., C. Echazarreta D. Roubik y Y. Moguel. 2014. Transgenic soybean pollen (Glycine max L.) in honey from the Yucatan peninsula, Mexico, Scientific reports, 4.

Winders, B. 2009. The vanishing free market: The formation and spread of the British and US food regimes, Journal of Agrarian Change, 9(3): 315-344.

Wooldridge, J. M. 2010. Introducción a la econometría. Un enfoque moderno, Cenage, Learning.

\section{ANEXOS}

Histograma de la distribución normal de los errores

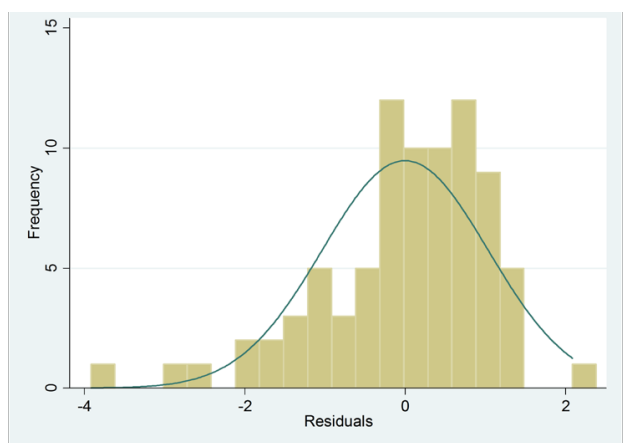

El histograma muestra la distribución normal de los errores, es decir, $\mu_{\mathrm{i}}$ (diferencia entre el valor real y el valor obtenido por el modelo).

La prueba de normalidad (pnorm) permite apreciar que los errores se distribuyen de manera normal. 


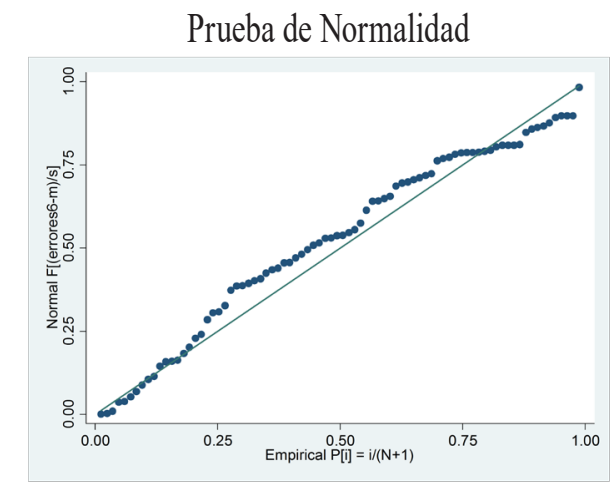

Fuente: Elaboración propia en STATA 12 con datos de la encuesta a apicultores realizada en Junio de 2015.

Con respecto a la prueba estat vif, que corresponde a la existencia de multicolinealidad, la prueba del factor inflación de la varianza es cercano a uno, la varianza es constante por lo tanto no hay multicolinealidad.

\begin{tabular}{r|cr} 
Variable & VIF & 1/VIF \\
\hline distancidu Y & 1.03 & 0.967348 \\
nmerodecol S & 1.03 & 0.967348 \\
\hline Mean VIF & 1.03 &
\end{tabular}

Para la prueba de heteroscedasticidad se utilizó la prueba Breusch-PaganGeoffrey (comando estat hettest) donde el valor de $\mathrm{X}^{2}$ (chi cuadrada) es igual a 0.65 menor que el valor de cuadros de 3.84 , por lo tanto, no hay heteroscedasticidad.

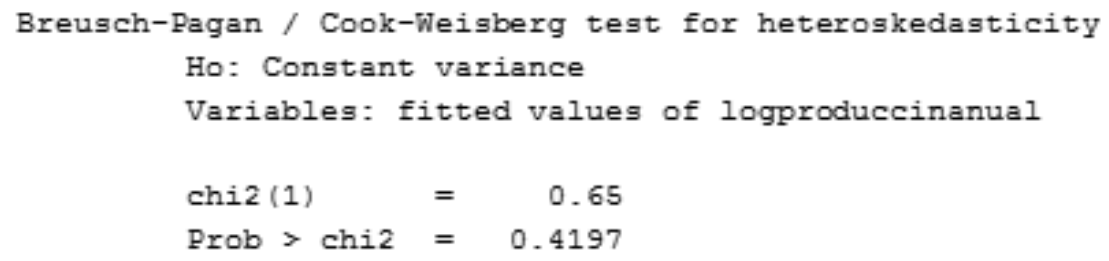

